\title{
O TRABALHO INFANTIL DOMÉSTICO E SUAS IMPLICAÇÕES NO CENÁRIO JURÍDICO BRASILEIRO
}

\section{Ozório Vicente Netto}

Mestre em Direito pela Universidade Federal do Espírito Santo - UFES (Vitória-ES). Graduado em Direito pela Universidade Federal do Espírito Santo (UFES). Professor de Direito do Trabalho na Faculdade Castelo Branco (Colatina/ES). Advogado trabalhista.

\section{Delma Crestan Ramos}

Bacharela em Direito pela FUNCAB - Faculdade Castelo Branco (Colatina-ES).

\section{Luciano Souto Dias}

Mestrando em Direito Processual pela Universidade Federal do Espírito Santo - UFES (Vitória-ES). Mestre em Direito Internacional Público pela UPAP (Assunção-PY). Especialista com pós-graduação lato sensu em Direito Civil e Processual Civil, pela Fadivale (Governador Valadares-MG). Professor titular de Direito Processual Civil e Prática de Processo Civil na graduação e pós-graduação da Fadivale. Coordenador de turma de pós-graduação em Direito Processual Civil sobre o Novo CPC na Fadivale. Conciliador do CEJUS (Centro Judiciário de Solução de Conflitos), do Tribunal de Justiça de Minas Gerais (TJMG). Advogado civilista.

Resumo: A pesquisa tem por escopo primordial a análise sobre o trabalho infantil doméstico. A princípio, o estudo recai sobre o trabalho infantil no Brasil, abordando o conceito e a evolução histórica, destacando as formas de trabalho infantil, prática por vezes de difícil constatação. São abordadas as legislações e princípios norteadores dos direitos dos menores, com destaque para as formas de combate ao trabalho infantil por meio do estudo de diversas literaturas e artigos científicos sobre o tema. O trabalho aponta caminhos para a atuação no combate ao trabalho infantil doméstico, a partir da análise de suas causas, consequências e legislações aplicáveis, com o objetivo de fomentar o debate sobre os entraves e as dificuldades no enfrentamento da questão.

Palavras-chave: Crianças. Adolescentes. Trabalho infantil doméstico. Implicações no cenário jurídico. Erradicação.

Sumário: 1 Introdução - 2 Definição conceitual e evolução histórica do trabalho infantil - 3 Evolução da legislação brasileira quanto ao trabalho infantil - 4 Proibição do trabalho infantil noturno, perigoso, insalubre e penoso - $\mathbf{5}$ As formas de trabalho permitidas aos menores - $\mathbf{6}$ Apontamentos sobre o trabalho infantil doméstico - $\mathbf{7}$ Combate ao trabalho infantil doméstico - $\mathbf{8}$ Conclusão - Referências 


\section{Introdução}

A pesquisa aborda e convida a uma reflexão sobre o trabalho infantil doméstico e suas implicações no cenário jurídico brasileiro. O trabalho infantil no Brasil é um grande problema social, pois influencia diretamente no desenvolvimento das crianças e dos adolescentes que, desde muito cedo, passam a desenvolver atividades laborativas que, inclusive, interferem negativamente no processo educacional.

Na maioria das vezes, o trabalho infantil é realizado em ambientes perigosos e em condições que afetam o desenvolvimento psicológico, físico, social e moral dos menores. A maioria das crianças que trabalha tem seu rendimento escolar prejudicado e serão candidatas ao abandono escolar.

O objetivo do presente estudo é discorrer sobre as implicações jurídicas quanto ao trabalho infantil doméstico no cenário brasileiro de forma a permitir análises quanto às formas de exploração do trabalho infantil e as normas aplicáveis. Para bem atingir o objetivo proposto, é utilizada como metodologia a pesquisa bibliográfica, procedimento apto a possibilitar a demonstração das diversas correntes e posicionamentos sobre o tema.

A relevância do tema que constitui objeto do estudo encontra-se tanto no contexto jurídico quanto no âmbito social, já que aborda situações corriqueiras no cenário das relações empregatícias, que, por conseguinte, geram relevantes consequências jurídicas.

Por assim ser, o estudo destaca as formas de exploração do trabalho infantil, bem como os órgãos de combate, demonstrando os danos que essa atividade pode causar à saúde psíquica - e consequentemente a sua interferência no desenvolvimento e na educação - das crianças e dos adolescentes.

\section{Definição conceitual e evolução histórica do trabalho infantil}

A definição de trabalho infantil, no pertinente à idade mínima de admissão ao emprego, pode ser extraída da Convenção 138 da OIT - Organização Internacional do Trabalho, promulgada por meio do Decreto n 4.134/2002 e ratificada pelo Brasil em 28.06.2011. No que concerne à idade mínima para admissão ao emprego, a Convenção estabelece o seguinte:

Artigo $1^{\circ}$

Todo País-Membro em que vigore esta Convenção, compromete-se a seguir uma política nacional que assegure a efetiva abolição do trabaIho infantil e eleve progressivamente, a idade mínima de admissão a 
emprego ou trabalho a um nível adequado ao pleno desenvolvimento físico e mental do adolescente.

Artigo $2^{\circ}$

1. Todo Membro que ratificar esta Convenção especificará, em declaração anexa à ratificação, uma idade mínima para admissão a emprego ou trabalho em seu território e nos meios de transporte registrados em seu território; ressalvado o disposto nos Artigos 4ㅇ e $8^{\circ}$ desta Convenção, nenhuma pessoa com idade inferior a essa idade será admitida a emprego ou trabalho em qualquer ocupação.

[...]

3. A idade mínima fixada nos termos do parágrafo 1ํ deste Artigo não será inferior à idade de conclusão da escolaridade obrigatória ou, em qualquer hipótese, não inferior a quinze anos. (BRASIL, 2002, p. 02)

Os países signatários da Convenção, entre eles o Brasil, comprometeram-se a estabelecer em suas legislações idades mínimas para o trabalho infantil, de modo a ter como parâmetro a idade em que cessa a obrigação escolar.

Santos (2013, p. 892) define o conceito de trabalho infantil como "aquele realizado por crianças e adolescentes que estão abaixo da idade mínima para entrada no mercado de trabalho, segundo a legislação vigente de cada país". No Brasil, o conceito de trabalho infantil adotado está definido no Plano Nacional de Prevenção e Erradicação do Trabalho Infantil e Proteção ao Adolescente Trabalhador, cujo teor define que o labor infantil se refere às atividades econômicas e/ou de sobrevivência, com ou sem finalidade de lucro, remuneradas ou não, realizadas por crianças ou adolescentes em idade inferior a 16 (dezesseis) anos, ressalvada a condição de aprendiz a partir dos 14 (quatorze) anos, independentemente da sua condição ocupacional (OLIVEIRA, 2012).

$\mathrm{O}$ trabalho infantil abrange todo tipo de trabalho proibido às crianças e adolescentes, quer pela idade, quer pelo risco que apresenta à sua integridade (SANTOS, 2013, p. 892).

Desde os tempos mais remotos, a exploração do trabalho infantil sempre esteve presente na sociedade, já que, ao longo do tempo, as crianças participaram ativamente das variadas funções a elas designadas como meio de ajudar suas famílias e a própria comunidade em que viviam (LIBERATI; DIAS, 2006). Na Antiguidade, o trabalho do menor voltava-se para um sistema de produção familiar, tipicamente de subsistência. Tinha finalidade meramente artesanal, não se afastando do âmbito doméstico. A profissão passava de pai para filho, o caráter de aprendizagem era sua principal característica (NASCIMENTO, 2003). 
Na idade média, em que imperavam as corporações de ofício, o menor aprendiz, sujeito aos ensinamentos do mestre e do companheiro, "realizava atividades produtivas também com o caráter marcadamente didático” (NASCIMENTO, 2010, p. 878), segundo a disciplina das diferentes corporações de ofício medievais. Contudo, foi com a Revolução Industrial que o trabalho infantil passou a ser aproveitado em larga escala, conforme asseveram Liberati e Dias (2006, p. 13):

No que se refere ao trabalho infanto-juvenil em atividades independentes, em que crianças e adolescentes figuravam como verdadeiros empregados, no exercício de funções intimamente ligadas a aspectos econômicos, convém reportar-se aos séculos XVIII e XIX, mais precisamente à Grã-Bretanha, berço da Revolução Industrial.

A Revolução Industrial mudou a estrutura econômico-familiar e a produção em larga escala, a partir da utilização de máquinas, e fez surgir novos empregos, o que resultou na busca desenfreada por mão de obra para suprir a demanda. Assim sendo, crianças pobres eram retiradas dos orfanatos em troca de alimento, moradia e jornada de trabalho, que poderia chegar a dezesseis horas diárias (MARQUES; SILVA, 2013).

Com efeito, famílias em busca de novas oportunidades começaram a deslocar-se dos campos para as cidades diante da grande oferta de empregos nas indústrias. Os empregadores, por sua vez, buscavam mão de obra barata e de fácil controle, acarretando o ingresso principalmente de mulheres e crianças nos pátios fabris. Durante toda a Revolução Industrial, até o período de maior crescimento (conhecido como industrialização madura), efetivamente o que ocorreu foi um longo período de exploração do trabalho de crianças, adolescentes e mulheres, pelo simples fato de trazerem mais lucros aos industriais, haja vista a facilidade na exploração desse tipo de mão de obra (LIBERATI; DIAS, 2006).

Destarte, a exploração da mão de obra de crianças e adolescentes não era vista como problema social até o período da Revolução Industrial, ocasião em que o ganho das crianças deixou de ser uma mera ajuda para as famílias e se tornou efetivamente um acréscimo monetário para ajudar no sustento das famílias (GRUNSPUN, 2000).

Com efeito, o anseio por melhores condições de vida tornou a exploração do trabalho infantil, durante o período da industrialização, essencial para as famílias, haja vista os salários irrisórios percebidos pelos operários. Logo, a proibição do trabalho dessas crianças geraria um maior empobrecimento das famílias, que sequer possuíam condições mínimas de subsistência. As consequências advindas daquela exploração da mão de obra infantil, porém, foram extremamente negativas, conforme exposto por Liberati e Dias (2006, p. 15): “o analfabetismo, o 
aumento da pobreza, inúmeras doenças e mutilações, assim como o enorme desgaste físico e o comprometimento do desenvolvimento desses jovens, em razão da jornada excessiva de trabalho".

A luta pela garantia de melhores condições para as crianças e adolescentes evoluiu de forma gradativa. Os movimentos para o combate ao trabalho infantil perduraram por todo o século XIX e culminaram nas chamadas Leis de Fábrica (Factory Acts), que introduziram medidas protetivas, bem como regulamentaram direitos no período de 1819 a 1867 (LIBERATI; DIAS, 2006). Destarte e com vistas a corrigir esse cenário, diplomas normativos que restringiram a possibilidade de utilização de mão de obra de crianças e adolescentes foram surgindo pelo mundo ao longo do tempo.

No Brasil, até o final do século XIX, não havia qualquer regulamentação de proteção ao trabalhador. A economia era basicamente agrícola e baseada na mão de obra escrava (NASCIMENTO, 2003). Nesse período, constataram-se enormes atrocidades cometidas contra os filhos dos escravos e crianças órfãs, que, assim como os escravos adultos, eram submetidas ao trabalho pesado durante várias horas do dia (LIBERATI; DIAS, 2006). Nascimento (2003) destaca que o trabalho escravo era utilizado nos mais diversos ramos de atividades, tais como: fazendas, lavouras, transporte de pessoas e cargas, comércio e serviços domésticos.

Assim o período da escravidão caracterizou-se pela existência de crianças escravas em diversas atividades laborais, de modo que, no campo, na mineração e nas lavouras, os meninos escravos começavam a executar trabalhos desde muito novos. Convém ressaltar, a título de exemplo, que um negro com 14 anos de idade era considerado mercadoria valiosa nas mãos dos seus senhores. As jovens negras também possuíam uma vida difícil, pois, além das atividades domésticas, eram objetos dos desejos sexuais dos seus proprietários (LIBERATI; DIAS, 2006).

As crianças escravas até a idade de 5 ou 6 anos eram tratadas pelos senhores como animais de estimação, de maneira que, após essa idade, eram colocadas juntas aos demais escravos e submetidas a trabalhos diários e exaustivos (LIBERATI; DIAS, 2006). Nesse cenário, inúmeras revoltas ocorreram para acabar com as péssimas condições a que estavam submetidos os trabalhadores escravos, entretanto, o processo de decadência da escravidão estendeu-se por longos 50 anos, que culminou na abolição alcançada, em 1888, por meio da Lei Áurea, assinada pela Princesa Isabel (LIBERATI; DIAS, 2006).

Não obstante e em que pese tenha representado grande avanço histórico, a abolição da escravatura em nada melhorou a vida dos escravos e de sua prole, haja vista que esses se viram livres, porém sem qualquer meio de subsistência, já que não possuíam profissão, terra ou qualquer ajuda. Relatos afirmam que nessa 
época inúmeras crianças foram jogadas, a esmo, nas ruas. Aliado a isso o país vivia um período de crise econômica que acarretou, juntamente com a falta de integração social entre os escravos recém-libertos e a sociedade, o aumento da marginalização (LIBERATI; DIAS, 2006).

Com o surgimento da indústria, ainda que tenha havido a imigração em massa de europeus para o Brasil para substituir a mão de obra escrava no campo, muitos jovens trabalhadores foram recrutados na condição de aprendizes para laborar nas oficinas e fábricas, isso porque a experiência do período de escravidão já havia demonstrado que o infante era mão de obra dócil, barata e de fácil adaptação ao labor (GRUNSPUN, 2000).

Nesse sentido afirmam Liberati e Dias (2006, p. 22):

Assim, o trabalho infantil se expandiu rapidamente no Brasil com o processo de industrialização do país, no final do século XIX e no início do século XX. E, a exemplo da Europa, os empregadores das indústrias no Brasil constataram, com a escravidão, que as crianças representavam mão-de-obra mais barata, facilmente adaptável e manipulada com extrema destreza, dada a sua ingenuidade.

O desenvolvimento industrial no Brasil, marcado por transformações nas esferas social, política e econômica, e principalmente pelas lutas abolicionistas, imprimiu novo olhar sobre a ideia que se tinha do trabalho. O que antes era considerado obrigação dos escravos passou a ser visto como instrumento de dignificação do homem. Houve, portanto, a necessidade de se inverter os valores. Sob a alegação de estarem cumprindo com esse papel social, após a Lei do Ventre Livre (1871), as famílias burguesas buscavam suprir a ausência da mão de obra escrava por meio do trabalho de crianças e de adolescentes, que recebiam recompensas pelos trabalhos prestados às suas novas famílias, proporcionalmente à idade e à qualidade dos serviços. Os meninos eram absorvidos nos trabalhos braçais e as meninas, em sua maioria, nos trabalhos domésticos (RIZZINI; FONSECA, 2002).

Assim, nos dizeres de Veronese e Custódio (2013, p. 86), “não há dúvidas de que a exploração dessa atividade doméstica tem suas raízes mais profundas no regime de escravidão brasileira, que perdurou até o século XIX". A própria relação de confiança gerada entre os senhores e os escravos, e a situação de submissão e de ser devedor de caridade, legitimou a exploração do labor infantil no âmbito doméstico (VERONESE; CUSTÓDIO, 2013).

A origem histórica do trabalho infantil está intimamente relacionada ao estudo de sua evolução legislativa, que será objeto de análise no próximo capítulo. 


\section{Evolução da legislação brasileira quanto ao trabalho infantil}

O trabalho infantil no Brasil expandiu-se rapidamente no final do século XIX e no início do século $X X$, o país estava em pleno processo de industrialização e os empregadores de indústrias descobriram que as crianças representavam uma mão de obra a mais com menos custos (LIBERATI; DIAS, 2006).

Antes do advento da Consolidação das Leis Trabalhistas, a legislação existente em relação ao trabalho do menor era esparsa, sendo aplicada da mínima forma, deixando importantes direitos à margem da proteção legal (NASCIMENTO, 2003).

A primeira lei de proteção aos menores surgiu após a abolição da escravatura, foi editada pelo Decreto № 1.313, de 17 de janeiro de 1891, e concedia aos menores os seguintes direitos:

(a) proibia o emprego de menores de doze anos no trabalho; (b) limitava a duração da jornada de trabalho; (c) autorizava a contratação de menores aprendizes a partir dos oito anos; (d) proibia o menor de exercer determinados tipos de trabalho que eram considerados perigosos à saúde (NASCIMENTO, 2003, p. 55).

O Decreto no 17.943-A, de 12 de outubro de 1927, instituiu a Consolidação das Leis de Proteção aos Menores, reconhecido como Código de Menores de 1927 (VERONESE; CUSTÓDIO, 2013, p. 61). A legislação tratava especialmente dos menores que se encontravam em situação irregular, disciplinando casos excepcionais como o de menores infratores, carentes e desajustados. 0 Código de Menores também disciplinava relações de trabalho não empregatícias, proibia o trabalho de menores de 18 anos como operários em condições insalubres ou perigosas e regulava o amparo concernente à assistência e à proteção ao desenvolvimento físico, mental e psicológico dos menores (NASCIMENTO, 2003, p. 59).

A Constituição de 1934 determinou a proibição do trabalho infantil para menores de 14 anos, o trabalho noturno a menores de 16 anos e, nas indústrias, também o trabalho insalubre a menores de 16 anos (artigo 121, §1ํㅡ, alínea "d"). As Constituições de 1937 e de 1946 mantiveram as disposições contidas na Constituição de 1934 (NASCIMENTO, 2003, p. 61).

O Decreto-Lei oㅜ 5. 452, de 1.5.1943, que entrou em vigor em 10.11.1943, instituiu a CLT - Consolidação das Leis Trabalhistas, que trouxe diversas inovações, entre elas um capítulo específico tratando de normas especiais de tutela e proteção do trabalho do menor que, de acordo com Nascimento (2003, p. 60), regulava: 
(a) a idade mínima para o trabalho; (b) trabalhos proibidos; (c) a duração da jornada de trabalho; (d) a admissão ao empregado; (e) a expedição da carteira profissional; (f) os deveres dos responsáveis legais e dos empregadores em relação ao menor; e (g) a aprendizagem dentre outras disposições de proteção.

Assim, as inovações trazidas pela CLT, de certa forma, passaram a dar maior atenção ao menor trabalhador.

Posteriormente, a Constituição de 1967 manteve as mesmas normas referentes ao trabalho do menor já existentes nos textos constitucionais anteriores, porém a idade mínima para o trabalho passou a ser de 12 anos (NASCIMENTO, 2003, p. 61). Houve uma mobilização da sociedade brasileira, que começou a se interessar, bem como a discutir a situação do menor, dando-lhe uma maior importância, com o escopo de estabelecer uma política de proteção integral (NASCIMENTO, 2003, p. 62).

A Constituição Federal de 1988 ampliou a idade do trabalho infantil para 14 anos, bem como estabeleceu novo padrão na área da infância (LIBERATI e DIAS, 2006, p. 25). De acordo com Veronese e Custódio (2013, p. 119):

A Constituição da República Federativa do Brasil, promulgada em 5 de outubro de 1988, trouxe ao universo jurídico brasileiro a Teoria da Proteção Integral da Organização das Nações Unidas (ONU), revogando definitivamente a Doutrina do Direito do Menor, vigente no Código de Menores, Decreto n. 17.943-A, de 12 de outubro de 1927, assim como na Doutrina da Situação Irregular, vigente no Código de Menores, Lei n. 6.697, de 10 de outubro de 1979. É a emergência de um novo ramo jurídico, denominado Direito da Criança e do Adolescente.

O artigo 227 da Constituição Federal incorporou em seu caput o princípio da proteção integral:

Art. 227. É dever da família, da sociedade e do Estado assegurar à criança, ao adolescente e ao jovem, com absoluta prioridade, o direito à vida, à saúde, à alimentação, à educação, ao lazer, à profissionalização, à cultura, à dignidade, ao respeito, à liberdade e à convivência familiar e comunitária, além de colocá-los a salvo de toda forma de negligência, discriminação, exploração, violência, crueldade e opressão. (BRASIL, 2013, p. 115)

Moraes (apud NASCIMENTO, 2003, p. 65) preleciona princípios que a Constituição Federal de 1988 consagrou na proteção do menor: 
Princípio da idade mínima - arts. 7으, XXXIII, e 227, §3ํㅡ, I;

Princípio da tutela especial - arts. 7으, XXXIII, e 227, §3ำ, I;

Princípio da aprendizagem e formação para o trabalho - arts. 7으, XXXIII, e 214;

Princípio das garantias trabalhistas - arts. 7으, XXXIII, e 227 §3ํㅡ, II;

Princípio da garantia da educação (qualificação para o trabalho) - art. 205.

A Lei no 8.069, de 13.7.1990 (Estatuto da Criança e Adolescente - ECA), que regula a proteção do menor, revogou o Código de Menores, trazendo uma nova visão na forma de garantir e tutelar os direitos concernentes aos menores (LIBERATI; DIAS, 2006, p. 70). O Estatuto da Criança e do Adolescente também adotou o princípio da proteção integral, tendo como fundamento o pleno desenvolvimento físico e mental das crianças e adolescentes. Nas palavras de Nascimento (2003, p. 65-66), “o referido estatuto rompeu com toda a sistemática até então tradicionalmente adotada no tratamento das questões relacionadas aos menores, trazendo alterações significativas de conteúdo e método".

Ademais, o ECA distinguiu a criança do adolescente - sendo a criança a pessoa com idade de até 12 anos incompletos e o adolescente aquela com idade entre 12 e 18 anos -, além da importante mudança terminológica reconhecendo a criança e o adolescente como sujeitos (VERONESE; CUSTÓDIO. 2013, p. 123). O novo estatuto abandonou o conceito assistencialista fortemente presente no Código de Menores de 1927 e 1979, para conseguir mais efetividade no que concerne à criança e ao adolescente, por meio de programas socioeducativos (NASCIMENTO, 2013, p. 66).

As atividades laborativas noturnas, penosas, insalubres ou perigosas à formação e ao desenvolvimento do menor ficaram proibidas a partir do Estatuto da Criança e do Adolescente (LIBERATI; DIAS, 2006, p. 72). Importante ressaltar que o artigo 63 do Estatuto determina o cumprimento do disposto no inciso III, §3o, do artigo 227 da Constituição Federal, ao regulamentar a garantia de acesso e frequência do menor ao ensino regular (NASCIMENTO, 2003, p. 67).

Desse modo, fica bem claro que o Estatuto da Criança e do Adolescente provocou mudanças com relação ao tratamento dos menores, conforme descreve Nascimento (2003, p. 68):

O Estatuto da Criança e do Adolescente estabeleceu uma profunda e radical mudança em relação ao tratamento dos menores no Brasil, disciplinando, para a garantia da proteção integral das crianças e dos adolescentes, que compete à família, à sociedade e ao Estado o 
dever prioritário de assegurar-Ihes o direito à vida, à saúde, à alimentação, à educação, ao lazer, à profissionalização, à cultura, à dignidade, ao respeito, à liberdade e à convivência familiar e comunitária.

O Estatuto estabeleceu uma política de proteção às crianças e aos adolescentes de modo que seu principal objetivo consistiu em resguardar seus direitos, assegurando proteção integral contra as formas de violação e buscando a erradicação do trabalho infantil doméstico (VERONESE; CUSTÓDIO, 2013).

Posteriormente, com a Emenda Constitucional no 20, de 15.12.1998, houve um aumento da idade mínima para o início do trabalho, que passou de 14 para 16 anos, fato que complementou o quadro de proteção existente em relação à criança e ao adolescente (NASCIMENTO, 2003, p. 65).

\section{Proibição do trabalho infantil noturno, perigoso, insalubre e penoso}

Prevalece a proibição de trabalho a menor de 18 anos quando se trata de trabalho noturno, insalubre ou perigoso. Santos (2013, p. 892) destaca essa proibição e acrescenta que:

[...] qualquer trabalho que importe em prejuízo ao desenvolvimento físico, psíquico, moral e social das crianças ou que se desenvolva em locais prejudiciais à moralidade não pode ser exercido por crianças ou adolescentes com idade inferior a 18 anos. É o que estabelecem os artigos 403 a 405 da CLT, que juntamente com os dispositivos constitucionais, e, também com as disposições previstas no Estatuto da Criança e do Adolescente, além da legislação internacional aplicável, fixam os parâmetros de idade mínima para o trabalho em diferentes atividades.

A vedação do trabalho noturno aos menores de 18 anos encontra fundamento legal tanto no artigo $7^{\circ}$ da Constituição Federal quanto no art. 404 da Consolidação das Leis do Trabalho e no inciso I do art. 67 do Estatuto da Criança e do Adolescente.

Embora a Constituição tenha vedado o trabalho noturno aos menores de 18 anos, ela não definiu o conceito, tampouco a duração da jornada de trabalho, todavia, essa proibição alicerça-se nos mesmos fundamentos que disciplinam a tutela especial dessa modalidade de jornada de trabalho, quais sejam: fundamentos de ordem fisiológica, uma vez que ocasiona maior cansaço do que o trabalho 
prestado durante o dia; e fundamento de ordem familiar e social, haja vista que no trabalho noturno o período de descanso e os hábitos da vida social não se harmonizam (NASCIMENTO, 2003, p. 93).

Outra justificativa relevante à proibição do trabalho noturno ao menor é a preocupação do legislador em resguardar o acesso e a frequência do menor à escola. Nesse contexto, justifica Nascimento (2003, p. 93):

Em qualquer modalidade de trabalho que o menor esteja atuando, a compatibilidade com a frequência escolar deve ser preservada. Nessa linha de ideias e considerando que geralmente o horário noturno é o tempo necessário para o menor se dedicar aos estudos e frequentar uma instituição de ensino visando ao seu aperfeiçoamento intelectual e sua formação profissional e moral, correta é a vedação do trabalho noturno aos menores de 18 anos.

Considera-se trabalho perigoso o que, por sua natureza ou método de trabaIho, implique o contato direto com substâncias inflamáveis, com explosivos, com eletricidade e em condições de risco acentuado (CAMPOS, 2012, p. 110).

Trata-se de conceito extraído do artigo 193 da CLT, como se observa:

Art. 193. São consideradas atividades ou operações perigosas, na forma da regulamentação aprovada pelo Ministério do Trabalho e Emprego, aquelas que por sua natureza ou métodos de trabalho, impliquem risco acentuado em virtude da exposição permanente do trabalhador a:

I - inflamáveis, explosivos ou energia elétrica;

II - roubos ou outras espécies de violência física nas atividades profissionais de segurança pessoal ou patrimonial.

§1으 0 trabalho em condições de periculosidade assegura ao empregado um adicional de $30 \%$ (trinta por cento) sobre o salário sem os acréscimos resultantes de gratificações, prêmios ou participações nos lucros da empresa.

$\S 2$ O $\mathrm{O}$ empregado poderá optar pelo adicional de insalubridade que porventura Ihe seja devido.

§3 Serão descontados ou compensados do adicional outros da mesma natureza eventualmente já concedidos ao vigilante por meio de acordo coletivo

$\S 4^{\circ}$ São também consideradas perigosas as atividades de trabalhador em motocicleta (BRASIL, 2014, p. 795). 
Entende-se por insalubres as operações que, por sua natureza, condições ou métodos de trabalho, exponham os empregados a agentes nocivos à saúde, acima dos limites de tolerância fixados em razão do tempo de exposição aos seus efeitos, conforme dispõe o artigo 189 da CLT:

Art. 189 Serão consideradas atividades ou operações insalubres aquelas que, por sua natureza, condições ou métodos de trabalho, exponham os empregados a agentes nocivos à saúde, acima dos limites de tolerância fixados em razão da natureza e da intensidade do agente e do tempo de exposição aos seus efeitos (BRASIL, 2014, p. 795).

Nascimento (2003, p. 78), ao definir a insalubridade, aduz que "a palavra insalubridade é originada do latim e tem o significado daquilo que não é saudável, que é nocivo à saúde, que pode provocar doenças". Não obstante, o legislador, no artigo 190 do mesmo diploma legal, confere ao Ministério do Trabalho e Emprego a competência para regular a matéria (NASCIMENTO, 2003, p. 79). O quadro de atividades insalubres é regulado pela Norma Regulamentadora no 15 (NR-15) do MTE e seus 14 anexos, conforme leciona Nascimento (2003, p. 79):

Essa Norma Regulamentadora estabelece quais são os agentes insalubres e os classifica em três espécies: a) agentes físicos - são formas de energia (calor, ruído, radiações, frio, vibrações, umidade e outros); b) agentes químicos - são substâncias, compostos ou produtos possíveis de penetração no organismo pelo contato, cútis, ingestão, via respiratória (poeira, gases, vapores, névoas, fumo e outros); c) agentes biológicos - são os microorganismos, sic, diversos (vírus, bactérias, bacilos, parasitas, fungos e outros).

$\mathrm{Na}$ intenção de distinguir insalubridade de periculosidade, Grasiele Augusta Ferreira Nascimento, citada por Campos (2012, p. 110), aduz que “enquanto a periculosidade implica risco a vida ou a integridade física do empregado, a insalubridade implica em dano à sua saúde".

Embora tenha previsão expressa no texto constitucional (art. 7으, XXXII, $\mathrm{CF} / 88$ ), o trabalho penoso, para ser remunerado, depende de lei que o regulamente. Ao contrário dos trabalhos insalubres e perigosos que estão associados a determinados agentes agressivos, causadores de doenças ou acidentes, o trabaIho penoso caracteriza-se por provocar desgastes - e até envelhecimento precoce - em razão da natureza do serviço, do esforço requerido e da forma de execução (NASCIMENTO, 2003, p. 88). Cretella Júnior, citado por Nascimento (2003, p. 88), 
define o trabalho penoso como sendo "trabalho acerbo, árduo, amargo, difícil, molesto, trabalhoso, laborioso, doloroso, rude".

As atividades penosas podem provocar problemas de saúde que não são necessariamente doenças e caracterizam-se pelo desgaste acentuado que trazem ao trabalhador, como problemas de coluna, articulação, estomacais, transtornos e sofrimentos mentais, entre outros. A Organização Internacional do Trabalho - OIT, por sua vez, ao regular o trabalho do menor em condições penosas, o relaciona com medidas de segurança e medicina do trabalho, a fim de proibir atividades que exijam força muscular superior ao limite de força dos menores (NASCIMENTO, 2003).

Segundo Nascimento (2003, p. 77), as proibições do trabalho do menor de 18 anos, no pertinente à insalubridade, “visam proteger a saúde, a integridade física e a segurança do mesmo, que fica mais suscetível aos efeitos nocivos dos agentes insalubres que o trabalhador adulto". Já no que concerne ao trabalho perigoso, "visam proteger a saúde, a integridade física e a segurança do menor, que, em razão de sua imaturidade mental, não pode perceber os riscos potenciais que envolvem uma atividade" (NASCIMENTO, 2003, p. 85). E completa afirmando que "a proibição do trabalho dos menores em atividades penosas tem por objetivo assegurar que os mesmos atuem somente em ambiente de trabalho seguro e salubre, para garantir sua plena saúde, física e mental" (NASCIMENTO, 2003, p. 90).

o trabalho perigoso, insalubre ou penoso é proibido, mesmo que sejam disponibilizados pela sociedade empresária os Equipamentos de Proteção Individual - EPI. Trata-se de regra de caráter absoluto (CAMPOS, 2012, p. 114), inclusive reconhecida pelo Tribunal Superior do Trabalho, conforme se verifica através do julgado que ora se colaciona:

EMBARGOS DE DECLARAÇÃO. TRABALHO DO MENOR DE 18 (DEZOITO) ANOS E MAIOR DE 16 (DEZESSEIS) ANOS. ATIVIDADE INSALUBRE. OMISSÃO, OBSCURIDADE E CONTRADIÇÃO. INEXISTÊNCIA. NÃO PROVIMENTO. Não há falar em vício ensejador dos embargos de declaração, quando emerge das alegações recursais o mero inconformismo com a decisão desfavorável, sem a demonstração do enquadramento da hipótese nos artigos 897-A da CLT e 535 do CPC. A matéria foi expressamente analisada no v. acórdão embargado, que, ao analisar o recurso, consignou expressamente os motivos pelos quais entendeu que a proibição do trabalho do menor de 18 (dezoito) anos e maior de 16(dezesseis) anos se dá em caráter absoluto, não sendo afastada nem pelo uso de EPI. Embargos de declaração a que se nega provimento (ED-AIRR - 940-86.2006.5.13.0027 , Relator Ministro: Guilherme Augusto Caputo Bastos, Data de Julgamento: 25/05/2011, 2- Turma, Data de Publicação: DEJT 03/06/2011) (BRASIL, 2011, p. 01). 
Compete ao Ministério do Trabalho e Emprego a fiscalização e a autuação dos empregadores que utilizarem a mão de obra infantil em atividades perigosas, insalubres e penosas (CAMPOS, 2012, p. 114).

\section{As formas de trabalho permitidas aos menores}

No que tange à idade mínima para trabalhar, a Constituição Federal foi clara em proibir, no seu art. 7으, XXXIII, qualquer trabalho a menor de 16 anos, salvo na condição de aprendiz a partir dos 14 anos:

Art. $7^{\circ}$ XXXIII - proibição de trabalho noturno, perigoso ou insalubre a menores de dezoito e de qualquer trabalho a menores de dezesseis anos, salvo na condição de aprendiz, a partir de quatorze anos (BRASIL, 2013, 21).

Assim, tem-se como idade mínima para o trabalho infantil os 16 anos, salvo na condição de aprendiz a partir dos 14 anos, sendo proibido aos menores de 18 anos o trabalho insalubre, noturno, perigoso, penoso, prejudicial à saúde, segurança (SANTOS, 2013).

Não se deve generalizar no sentido de afirmar que as formas de trabalho do menor representam exploração ilegal/irregular de sua atividade, isso porque nossa legislação prevê formas lícitas de trabalho do menor. 0 próprio art. 69 do Estatuto da Criança e do Adolescente garante o direito à profissionalização aos adolescentes quando estabelece que:

Art. 69. 0 adolescente tem direito à profissionalização e à proteção no trabalho, observados os seguintes aspectos, entre outros:

I - respeito à condição peculiar de pessoa em desenvolvimento;

II - capacidade profissional adequada ao mercado de trabalho (BRASIL, 2015, p. 17).

Antes da Emenda Constitucional $n^{\circ}$ 20, que alterou a redação do inciso XXXIII do art. $7^{\circ}$ da Constituição Federal, dispondo ser proibido o trabalho noturno, perigoso ou insalubre a menores 18 anos e de qualquer trabalho a menores de 16 anos, salvo na condição de aprendiz, a partir dos 14 anos, poderiam ser destacadas várias formas de trabalho do menor autorizadas por lei:

$O$ gênero trabalho do menor comporta mais de uma modalidade. Primeira, o menor empregado, regido pela Constituição Federal e pela 
Consolidação das Leis do Trabalho (CLT, art. $3^{\circ}$ ). Segunda, o menor aprendiz empregado, também disciplinado pela CLT (art. 428). Terceira, o menor aprendiz não empregado, a que se refere também a CLT (art. 431). Há outras modalidades: o adolescente assistido, o trabaIho socioeducativo (Estatuto da Criança e do Adolescente, art. 67) e o trabalho familiar (CLT, art. 402) (NASCIMENTO, 2010, p. 884).

Tem-se, pois, imposto o limite da idade mínima de 16 anos para ingresso no mercado de trabalho em âmbito nacional, salvo na condição de aprendiz a partir dos 14 anos, e a proibição de trabalho insalubre, noturno, perigoso, penoso, prejudicial à saúde, segurança e moralidade de crianças e de adolescentes, assim considerados os menores de 18 anos de idade (SANTOS, 2013, p. 893).

Diante do que foi exposto, é possível concluir que, imposto o limite de idade para ingresso no mercado de trabalho, em regra, vedam-se as demais modalidades de trabalho infantil, salvo as autorizadas por lei.

\section{Apontamentos sobre o trabalho infantil doméstico}

Apesar de toda a evolução do século XXI, a exploração do trabalho infantil ainda é constante, conforme asseveram Marques e Silva (2013, p. 835):

\footnotetext{
Realmente, nas esquinas das cidades, ou nos campos interiores do Brasil, as cenas se repetem na ordinariedade da vida: milhares de crianças e adolescentes em situação de trabalho informal expõem suas vidas a inúmeros prejuízos de ordem biológica, social, física e moral, relegando seu futuro às amarras da exclusão social e perpetuando, pois, o círculo vicioso da matéria.
}

Logo e diante da repetição da exploração do trabalho infantil ao longo dos anos, o cenário se tornou corriqueiro para boa parte da população, fato que gerou um sentimento de aceitação, pois a maioria acredita que é melhor que a criança ou o adolescente esteja trabalhando do que se dedicando ao roubo ou ao uso de drogas (MARQUES; SILVA, 2013, p. 835-836).

O trabalho infantil doméstico é uma das formas de exploração dos menores de maior dificuldade de percepção, pois ocorre no contexto intrafamiliar, ou seja, no âmbito do espaço privado das famílias. Nas palavras de Veronese e Custódio (2013, p. 85) "o trabalho doméstico integra o conteúdo mais abrangente da exploração do trabalho infantil, colocando a criança e o adolescente numa perversa situação de exploração restrita ao campo da sua não percepção, de um verdadeiro esquecimento". 
Trata-se de exploração do trabalho infantil deixada por vezes de lado, haja vista a naturalidade com que é encarada a participação de crianças e adolescentes nos afazeres domésticos em suas casas ou nas de terceiros (RIZZINI; FONSECA, 2002, p. 8).

Conforme asseveram Rizzini e Fonseca (2002, p. 6-8), o trabalho infantil doméstico é aquele "que é realizado por crianças e adolescentes fora de suas casas. [...] executado em troca de um salário ínfimo ou de uma promessa de roupa, escola e alimentação", todavia, afirmam também que "grande parte desse tipo de trabalho é realizado pelas meninas em suas próprias casas, incluindo, a responsabilidade pelo cuidado dos irmãos menores". Nesse sentido, Veronese, citado por Santos (2013, p. 897), esclarece a distinção entre meros afazeres domésticos e exploração do trabalho infantil:

O compartilhamento de tarefas no espaço doméstico faz parte de todo o processo de socialização da criança e do adolescente que, na família, oferece sua parcela de contribuição para organização do espaço de vivência. Não se trata especificamente de ajuda, mas, sim, de efetiva responsabilidade, de acordo com suas condições de desenvolvimento físico e psicológico, a qual uma criança e um adolescente podem assumir. Trata-se, portanto, de uma forma coletiva e solidaria de vivência em comum. Não se pretende que a criança e o adolescente assumam responsabilidades, mas que, gradativamente, incorporem uma parcela de contribuição naquele espaço de convivência familiar de acordo com suas capacidades e cultura. No entanto, quando a criança e o adolescente assumem responsabilidades que são típicas de adultos e estão além de suas necessidades de desenvolvimento, pode-se encontrar uma forma de exploração do trabalho infantil doméstico pela própria família, pois não são todas as tarefas domésticas ajustadas as condições de desenvolvimento da criança e do adolescente. São notórios os casos de meninas que recebem a responsabilidade de cuidar dos irmãos mais novos diante da necessidade de as mães buscarem alternativas de sobrevivência no mercado de trabalho. Isso não se faz como etapa necessária ao desenvolvimento de qualquer criança e adolescente; antes de tudo, trata-se de uma forma de exploração do trabalho infantil doméstico, transfigurada a suposta virtude de ajuda a família.

Assim, Santos (2013, p. 897) entende que:

O trabalho infantil doméstico [...] pode estar caracterizado na realização de rotinas de afazeres imposta a crianças e adolescentes, 
que importem na privação ou limitação de seus direitos humanos fundamentais, com a exigência de trabalhos superiores as suas forças ou que Ihes traga prejuízos físicos, psicológicos, sociais, morais, ultrapassando a mera contribuição na organização e cuidado com o espaço em que habita.

As atividades realizadas no próprio âmbito familiar podem configurar trabaIho infantil doméstico, caso sejam exercidas de forma abusiva (SANTOS, 2013, p. 898).

\subsection{Causas e consequências do labor infantil doméstico}

A pobreza e o baixo grau de escolaridade estão diretamente interligados quando o assunto é a exploração do trabalho infantil. Em pleno século XXI, é inaceitável a existência dessa forma de exploração, tendo em vista que esse problema não atinge apenas suas vítimas, mas sim os seus autores, porquanto o que está sob enfoque é o próprio futuro da sociedade (DUTRA, 2007). O fator econômico, entretanto, não pode ser considerado o único causador do trabalho infantil, embora seja o fator principal. Nesse sentido, afirmam Veronese e Custódio (2013, p. 85):

Os indiciadores sobre o trabalho infantil doméstico não são apenas resultantes do acirramento da exclusão econômica e empobrecimento da população, mas, também, indicam uma continuidade da dinâmica histórica consolidada por práticas jurídicas institucionais, que sempre deslocaram a responsabilidade para crianças e adolescentes pela sua própria subsistência e também do grupo familiar.

Trata-se, portanto, de fenômeno de alta complexidade, determinado pela junção de diversos fatores, entre eles os olhares atribuídos pela sociedade e pela família a esses menores, bem como, no decorrer da história, a inexistência de direitos que visavam à proteção das crianças e dos adolescentes em diversas situações (VERONESE; CUSTÓDIO, 2013). Para ilustrar essa situação, transcreve-se um depoimento retirado do texto de Rizzini e Fonseca (2002, p. 17-18):

Salete, caçula de sete irmãos, nasceu em um distrito interiorano, na fronteira entre Rio Grande do Sul e Santa Catarina. Desde cedo, trabalhava junto aos demais membros de sua família como agregada na roça dos vizinhos: "pegava na enxada, andava de cavalo, fazia tudo 
igual aos irmãos". Porém, chegado seu décimo segundo aniversário, sua mãe anunciou que achara uma colocação para a menina. Salete lembra o desespero que sentiu ao separar-se da família: "Chorava, chorava tanto, que meu patrão disse que ia me chamar de 'Sal derrete' em vez de Salete"... Também lembra a longa rotina de trabalho diário: "Levantava cedo, antes do patrão e sua mulher ir para a roça porque eu que fazia café. Depois, cuidava dos quatro filhos a manhã inteira e ainda tinha que fazer o almoço. De tarde, a patroa ficava em casa enquanto eu ia para o riacho comum a trouxa desse tamanho de roupa para lavar... e, de noite, depois da janta, ainda tinha que arear as panelas e limpar a cozinha. Às vezes, ia até meia noite". Apesar do trabalho pesado e as saudades de casa, Salete não pensou em resistir contra a vontade de sua mãe. "A gente fazia o que ela mandava. Imagine se ela ia me deixar voltar para casa!". Aquele casal pagava bem e, quando chegava o fim do mês, a mãe estava sempre lá, à porta da cozinha deles, para receber "seu" pagamento.

Nessa toada e em que pese o ingresso do menor no trabalho doméstico na casa de terceiros depender de decisão de cunho familiar e também das oportunidades oferecidas, percebe-se que outros fatores ideológicos, como questões culturais, educacionais e econômicas, influenciaram no ingresso do menor no trabalho infantil doméstico (VERONESE; CUSTÓDIO, 2013, p. 87).

No depoimento em questão, verifica-se que o fator cultural de que os filhos devem obediência a seus pais, em uma relação de hierarquia, fez com que a menor não só aceitasse a situação, mas se sentisse satisfeita em desempenhar esse papel.

O trabalho infantil, portanto, tem sua compreensão no momento em que se analisam todos os elementos estruturantes, acrescidos às peculiaridades pertinentes de cada caso. Percebe-se que o trabalho infantil doméstico abrange várias causas sendo as mais evidentes as de cunho econômico, político e cultural (VERONESE; CUSTÓDIO, 2013, p. 88).

A baixa renda familiar é um estímulo à utilização de mão de obra infantil, outrossim, a desigualdade social, por ausência de políticas públicas adequadas, em muito contribui para essa situação. Conforme explicam Veronese e Custódio (2013, p. 89), “no Brasil é mais frequente o uso de trabalho infantil em relação à maior parte dos países da América Latina. Embora as condições econômicas de tais países sejam muito mais precárias que as condições brasileiras, é o fator social que explica o maior uso de mão de obra infantil".

A ausência de políticas econômicas é que gera marginalização social e desigualdades. Em nosso país, o trabalho infantil é utilizado como complemento do 
trabalho de renda dos pais ou responsáveis e, por tal motivo, sempre foi pouco valorizado (VERONESE; CUSTÓDIO, 2013).

A principal consequência para o menor em decorrência do labor infantil doméstico envolve a dificuldade de acesso à escola, em razão das longas jornadas, a evasão e o baixo nível de rendimento. Ademais, aspectos ergonômicos e condições de periculosidade e de insalubridade colocam em risco a saúde e a integridade dos menores, porque o trabalho doméstico, por se caracterizar como atividade que demanda esforço repetitivo, pode prejudicar o desenvolvimento do menor (VERONESE; CUSTÓDIO, 2013). O próprio Decreto nํ 6.481/2008 indica os riscos ocupacionais aos quais as crianças e adolescentes estão submetidos:

Esforços físicos intensos; isolamento; abuso físico, psicológico e sexual; longas jornadas de trabalho; trabalho noturno; calor; exposição ao fogo, posições antiergonômicas e movimentos repetitivos; tracionamento da coluna vertebral; sobrecarga muscular e queda de nível. Também destaca como prováveis repercussões a saúde a presença de: Afecções músculo-esqueléticas (bursites, tendinites, dorsalgias, sinovites, tenossinovites); contusões; fraturas; ferimentos; queimaduras; ansiedade; alterações na vida familiar; transtornos do ciclo vigília-sono; DORT/LER; deformidades da coluna vertebral (lombalgias, lombociatalgias, escolioses, cifoses, lordoses); síndrome do esgotamento profissional e neurose profissional; traumatismos; tonturas e fobias. (BRASIL, 2008, p. 05)

Os reflexos causados com a exploração do trabalho infantil são bem mais profundos do que se imagina, e a falta de investimento social que valorize o ser humano acaba gerando consequências para a estrutura política, econômica e social do país:

[...] Prova disto é o crescente deslocamento de crianças e adolescentes rumo ao exercício de atividades ilícitas, como o narcotráfico e a prostituição, ampliando desta forma o mercado do crime, que se mostra cada vez mais organizado em nossa sociedade, associando-se à violência e à impunidade (LIBERATI; DIAS, 2006, p. 108).

Nas palavras de Veronese e Custódio (2013, p. 248), “o trabalho infantil doméstico no Brasil é um fenômeno de larga extensão, decorrente de causas complexas referendadas por mitos culturais que legitimam e ocultam a condição de exploração da criança e do adolescente".

A realidade da exploração do trabalho infantil exige a implementação de novas perspectivas de enfrentamento, de modo que o Direito possa dar uma resposta 
mais eficaz para que haja efetivamente a proibição do trabalho infantil antes da idade mínima (MARQUES; SILVA, 2013).

\section{Combate ao trabalho infantil doméstico}

Apesar de o Brasil ser considerado como modelo no que tange à proteção formal contra o trabalho infantil, esse país tem muito que se aperfeiçoar para ser assim tratado (CAMPOS, 2012, p. 166). Para combater os altos índices de exploração infantil, o Estado delega suas responsabilidades a órgãos de proteção como o Ministério do Trabalho e Emprego, o Ministério Público e o Poder Judiciário (CAMPOS, 2012, p. 167).

O Ministério do Trabalho e Emprego, assim como os outros órgãos, desempenha papel fundamental no combate à exploração do trabalho infantil. No Brasil, o marco de criação da inspeção do trabalho infantil advém do Decreto no 1.313, de 17 de janeiro de 1891. Não obstante, vale ressaltar que, em 12 de setembro de 2002, o Brasil, por meio do Ministério do Trabalho e Emprego, instituiu a Comissão Nacional de Erradicação do Trabalho Infantil - CONAETI (CAMPOS, 2012, p. 167-168).

O papel do Ministério do Trabalho e Emprego é de extrema relevância na fiscalização do trabalho infantil, uma vez que combate, por exemplo, a aceitação da permanência de menores de 18 anos em estabelecimentos comerciais consumindo bebidas alcoólicas de madrugada (CAMPOS, 2012, p. 169).

Outrossim, outro importante órgão no combate à exploração do trabalho infantil é o Ministério Público Estadual, que, conforme Campos (2012, p. 169), é uma "instituição vocacionada à defesa da ordem jurídica e a promoção dos direitos fundamentais, seja no tocante ao cidadão visto de forma individual, seja de toda coletividade".

A atuação do Ministério Público do Trabalho, no que concerne ao combate ao trabalho infantil, compreende a fiscalização, a atuação judicial e também a elaboração de Termos de Ajustamento de Conduta - TAC que envolvem a matéria em questão, por meio dos quais muitos empregadores, inclusive, se comprometem a abster-se da utilização do trabalho infantil, sob pena de multa (CAMPOS, 2012, p. 171). Outro órgão de suma importância é o Poder Judiciário, que, após ser provocado, desempenha sua função da prestação jurisdicional e contribui com a erradicação do trabalho infantil ao punir seus exploradores (CAMPOS, 2012, p. 173).

O Conselho Tutelar, criado pelo Estatuto da Criança e do Adolescente, também atua de forma relevante no combate à exploração do trabalho infantil, pois recebe denúncias e encaminha as soluções dos problemas envolvendo a violação 
dos direitos das crianças e dos adolescentes, inclusive os que se relacionam com o trabalho infantojuvenil doméstico.

Veronese e Custódio (2013, p. 241) também aduzem que:

As ações de erradicação do trabalho infantil doméstico encontram um aliado importante nas ações das organizações não governamentais. A sociedade civil organizada exerce papel relevante no sistema de garantias de direitos da criança e do adolescente, na medida em que propõe ações e interfere na política de erradicação do trabalho infantil doméstico, pois sua proximidade com as comunidades locais oferece experiências significativas para transformações de acordo com as necessidades das crianças e dos adolescentes.

No entanto e apesar dos diversos órgãos voltados ao combate da exploração do trabalho infantil existentes, a erradicação do trabalho infantil doméstico é um processo que está em início de implantação no Brasil e enfrenta vários obstáculos que vão desde a implementação e a consolidação do sistema de garantias de direitos até a fragilidade das políticas públicas. Conforme os ensinamentos de Santos (2013, p. 930):

Os desafios para a erradicação do trabalho infantil doméstico na sociedade brasileira são muitos. Passam pela necessidade de desconstrução de mitos que sustentam a exploração do trabalho infantil, naturalizado e aceito pela sociedade, exigindo postura diversa dos atores sociais que visualizavam e convivem passivamente com essas práticas violadoras de direitos humanos, a fim de que denunciem os casos de exploração de trabalho infantil doméstico, seja na própria família ou em casas de terceiros. Campanhas publicitárias e divulgação de notícias na imprensa quanto os prejuízos decorrentes do trabalho em idade precoce devem ser permanentes.

A existência do problema da exploração do trabalho infantil não é consequência da ausência de dispositivos legais de proteção ao menor - pois existem vários dispositivos que visam à proteção da criança e do adolescente -, mas sim em razão do descumprimento das normas existentes e da deficiente capacidade de fiscalização do poder público (NASCIMENTO, 2003).

De acordo com Veronese e Custódio (2013, p. 239): “a fiscalização da exploração do trabalho infantil doméstico depende em boa parte de uma política de promoção dos direitos da criança e do adolescente. Isso porque a exploração do trabalho infantil doméstico realiza-se na inviabilidade do espaço privado". 
Dutra (2007, p. 140) acrescenta que: “o caminho da educação é uma das grandes saídas para a solução desse problema. É impossível pensar em educação de qualidade sem levar em conta o pensamento de Paulo Freire, considerando que a educação é a base para a transformação de qualquer sociedade".

A exploração do trabalho infantil é uma prática secular e rotineira em todo o mundo, inclusive no Brasil, que enfrenta desigualdades sociais enormes e as crianças são usadas para reforçar o orçamento doméstico (MARINHO, 2014).

O trabalho infantil doméstico está interligado com as causas econômicas, educacionais e políticas e afeta diretamente o desempenho da criança e do adolescente. Também por isso, são pouco conhecidas no universo popular as formas de exploração do trabalho infantil doméstico, notadamente ante esses elementos que consubstanciam o fortalecimento dos mitos do trabalho infantil (VERONESE; CUSTÓdIO, 2013).

É necessário que haja uma conscientização social, pois na maioria dos casos a exploração do trabalho infantil não existe de forma proposital, mas em razão da necessidade econômica das famílias dos menores (NASCIMENTO, 2003). A exploração do trabalho infantil encontra reforço em tradições e mitos culturais, porém essa visão atinge apenas crianças e adolescentes pobres, pois famílias com condições econômicas preferem inserir sua prole em boas escolas, no intuito de formar profissionais capacitados, para ingressar no mercado de trabalho no momento certo (SANTOS, 2013).

De acordo com Campos (2012, p. 179): “é necessário chamar a sociedade brasileira à ordem, ungindo em debates e construção de ideias e políticas públicas a procura de soluções, tendo presente que a erradicação das violências do trabaIho infantil é uma tarefa difícil, porém, não impossível".

É de suma importância, destarte, que mecanismos de combate ao trabalho infantil sejam colocados à disposição de toda a sociedade, inclusive com programas de reestruturação de famílias desagregadas e projetos que objetivem o recrutamento de crianças e adolescentes para as escolas. A cooperação dos jovens para a solução dos problemas sociais enfrentados pelas comunidades também é importantíssima, pois faz parte da construção de uma perspectiva democrática e participativa, até porque, a partir do momento que esses jovens assumem papel de ativistas para promover os direitos da criança e do adolescente, alcançam duplo papel, por exercerem ao mesmo tempo uma prática política mobilizadora e constituir uma oportunidade significativa de sensibilização de suas próprias famílias.

No entanto, o ativismo juvenil não se constrói apenas com a boa vontade da juventude em colaborar com os temas sociais. É imprescindivel que o Poder Público e a comunidade instituam ferramentas e 
oportunidades capazes de potencializar as ações juvenis (VERONESE; CUSTÓDIO, 2013, p. 234).

Torna-se imprescindivel que o valor incondicional do ser humano seja resgatado, no sentido de que a real compreensão da infância e da adolescência resulte na necessidade de proporcionar uma infância saudável, pois é uma fase importante no desenvolvimento humano. Apesar de toda a evolução legislativa e jurisprudencial existente, o pensamento social quase não se alterou em relação à exploração do trabalho infantil doméstico, e isso muito se deve à pouca visibilidade dessa forma de trabalho. Infelizmente, ainda existe na sociedade uma grande quantidade de pessoas que acreditam que crianças e adolescentes precisam trabalhar, mesmo antes do limite de idade prevista em lei, por terem o falso pensamento de que, assim, elas não ficarão ociosas nas ruas e serão impedidas de usar drogas (SANTOS, 2013, p. 919).

O mundo se torna injusto para as crianças que sofrem com a exploração do trabalho, na medida em que são pessoas indefesas, ainda em processo de formação, e que se submetem ao risco de aniquilação da infância, uma etapa que deveria ser de alegrias, brincadeiras, crescimento e aprendizagem infantil (BARBOSA; PEREIRA, 2014). Para Veronese e Custódio (2013, p. 237):

A erradicação do trabalho infantil doméstico deve ser amparada por uma nova concepção de emancipação das crianças e dos adolescentes, mas não se pode esquecer do papel central da família como instância de proteção e articulação das estratégias de desenvolvimento humano e social. Por isso, uma transformação social que se pretenda histórica exige a compreensão, o apoio e a participação ativa de toda família.

A legislação pode estimular mudanças sociais, mas é de suma importância a vontade política de seguir o mandamento constitucional de proteção à criança e ao adolescente, com a criação de mecanismos eficientes para combate e fiscalização da exploração do trabalho infantil doméstico. Somente com uma fiscalização severa será possível a erradicação do trabalho infantil. As crianças são o futuro e elas têm direito à felicidade, a desfrutar de sua infância e de serem adultas no momento certo.

\section{Conclusão}

Conforme foi possivel observar através do presente trabalho, apesar da existência de várias leis de proteção à criança e ao adolescente, a prática da exploração 
do trabalho infantil, inclusive o doméstico, ainda é muito comum. Muitas pessoas ainda pensam que é melhor uma criança trabalhar do que estar nas ruas, pensamento que se torna um obstáculo ao enfrentamento e a desconstrução desses mitos.

É de suma importância a fiscalização por parte dos órgãos de combate à exploração do trabalho infantil, bem como o envolvimento de toda a sociedade nesse processo, já que, para acabar com o mito criado ao longo do tempo, surge a necessidade da implementação de políticas com a finalidade de ampliar o canal entre a sociedade e o acesso às informações de interesse público e social voltadas à erradicação do trabalho de crianças e adolescentes.

A implementação de políticas públicas assistenciais capazes de auxiliar financeiramente as famílias dos menores em situação de pobreza pode contribuir para a redução do trabalho infantil doméstico. Também se torna necessária a promoção de campanhas educativas no sentido de inibir a sociedade a adquirir produtos fabricados a partir da exploração infantil, bem como de se utilizar da prática desse tipo de exploração.

A criança e o adolescente nos dias de hoje ainda são vítimas do trabalho infantil na medida em que são obrigadas a agir muitas vezes como adulto e a ver escapar a melhor parte da vida de um ser humano: a infância.

A exploração do trabalho infantil é um problema constante e que cabe a todos combatê-lo, tendo iniciativas que visem a erradicar a referida prática, com uma ação coletiva e universal, mesmo que somente as gerações futuras se beneficiem dos frutos.

\section{Child domestic work and its implications in the Brazilian legal scenario}

Abstract: The research has the primary scope to analysis of child domestic labor. At first, the study rests on child labor in Brazil, addressing the concept and historical evolution, highlighting the forms of child labor, a practice sometimes difficult finding. Laws and guiding principles of the rights of minors are discussed, highlighting ways of combating child labor through the study of literature and several scientific papers on the subject. The work shows the way for action to combat child domestic labor, based on the analysis of its causes, consequences and applicable laws, in order to foster debate on the obstacles and difficulties in addressing the issue.

Keywords: Children. Adolescents. Domestic child labor. Implications for legal scenario. Eradication.

Contents: 1 Introduction - $\mathbf{2}$ Conceptual Definition and historical evolution of child labor - $\mathbf{3}$ Evolution of the Brazilian law as child labor $\mathbf{- 4}$ Prohibition of night child labor, dangerous, unhealthy and painful $\mathbf{- 5}$ The forms of work permitted to minors - $\mathbf{6}$ Notes on child domestic labor $\mathbf{-} \mathbf{7}$ Combating child domestic labor - 8 Conclusion - References 


\section{Referências}

BARBOSA, Fernanda Pereira; PEREIRA, Maria Autelina. Evolução do trabalho infantil e sua proteção em âmbito mundial. Disponível em: <http://www.ambitojuridico.com.br/site/index. $\mathrm{php} /$ ?n_link=revista_artigos_leitura\&artigo_id $=12328 \&$ revista_caderno=25>. Acesso em: 22 jul. 2014.

BRASIL. Constituição da República Federativa do Brasil de 1988. Código 4 em 1. 9. ed. São Paulo: Saraiva, 2013

BRASIL. Consolidação das Leis do Trabalho. In: Vademecum. 6. ed. São Paulo: Revista dos Tribunais, 2014.

BRASIL. Lei no 8.069/1990 - Estatuto da Criança e do Adolescente. Disponível em: <http:// www.planalto.gov.br/ccivil_03/leis//8069.htm>. Acesso em: 25 ago. 2015.

BRASIL, Decreto no 4.134, de 15 de fevereiro de 2002. Disponível em: <http://www.planalto. gov.br/ccivil_03/decreto/2002/d4134.htm>. Acesso em: 11 ago. 2014.

BRASIL. Tribunal Superior do Trabalho. Embargos de declaração. Trabalho do menor de 18 (dezoito) anos e maior de 16 (dezesseis) anos. Atividade insalubre. ED-AIRR - 94086.2006.5.13.0027, Relator Ministro: Guilherme Augusto Caputo Bastos, Data de Julgamento: 25.05.2011, 2ª Turma, Data de Publicação: DEJT 03.06.2011). Disponível em: पhttp://www.tst.jus.br/consulta-unificada>. Acesso em: 15 nov. 2015.

BRASIL. Decreto $n^{\circ} 6.481,12$ de junho de 2008. Lista das piores formas de trabalho infantil. Disponível em: <http://www.planalto.gov.br/ccivil_03/_ato2007-2010/2008/decreto/ d6481.htm>. Acesso em: 10 nov. 2015.

CAMPOS, Marco Antônio Lopes. Proposições Jurídicas: Fonte de proteção Social do Trabalho Infantil. São Paulo: LTr, 2012. 190p.

DUTRA, Maria Zuila Lima. Meninas Domésticas, Infâncias Destruídas-Legislação e Realidade Social. São Paulo: LTr, 2007. 149p.

GRUNSPUN, Haim. O Trabalho das Crianças e dos Adolescentes. São Paulo: LTr, 2000. 160p.

LIBERATI, Wilson Donizeti; DIAS, Fábio Muller Dutra. Trabalho Infantil. São Paulo: Malheiros, 2006. 175p.

MARINHO, Rosa Angela S. Ribas. A Exploração da Mão de Obra Infantil. Disponível em: <http://jus.com.br/artigos/1661/a-exploracao-da-mao-de-obra-infantil>. Acesso em: 23 jul. 2014.

MARQUES, Rafael Dias; SILVA, Regina Duarte da et al. Estudos Aprofundados MPT Ministério Público do Trabalho - Trabalho Infantil: Atualidades e Perspectivas. 2. ed. Salvador: Juspodivm, 2013. 1477 p.

NASCIMENTO, Amauri Mascaro. Curso de Direito do Trabalho. 25. ed. São Paulo: Saraiva, 2010. 1461p. 
NASCIMENTO, Nilson de Oliveira. Manual do Trabalhado do Menor. São Paulo: Ltr, 2003. $166 p$.

OLIVEIRA, Isa de. Trabalho Infantil: conceito de desafios. Disponível em: <http://www. promenino.org.br/Default. aspx?Tabld=77\&Conteudold=baf24874-f2dd-40aa-b4597ba66064b852>. Acesso em: 10 mar. 2014.

RIZZINI, Irene; FONSECA Claudia. As meninas e o universo do trabalho doméstico no Brasil. Aspectos históricos, culturais e tendências atuais. Disponivel em: <http:// www.ciespi.org. br/publicacoes/artigos?task=download\&file...pdf >. Acesso em: 10 ago. 2014.

SANTOS, Elisiane dos et al. Estudos Aprofundados MPT Ministério Público do Trabalho - Desafios no Combate ao Trabalho Infantil Doméstico sob a Perspectiva da Atuação do Ministério Público do Trabalho. 2. ed. Salvador: Juspodivm, 2013. 1477p.

VERONESE, Josiane Rose Petry; CUSTÓDIO, André Viana. Trabalho Infantil Doméstico no Brasil. São Paulo: Saraiva, 2013. 276p.

Recebido em: 09.12.2015

Pareceres: 18.06 .2016 e 05.07.2016

Aprovado em: 12.07.2016

Informação bibliográfica deste texto, conforme a NBR 6023:2002 da Associação Brasileira de Normas Técnicas (ABNT):

VICENTE NETTO, Ozório; RAMOS, Delma Crestan; DIAS, Luciano Souto. O trabalho infantil doméstico e suas implicações no cenário jurídico brasileiro. Direitos Fundamentais \& Justiça, Belo Horizonte, ano 10, n. 34, p. 223-248, jan./jun. 2016. 